\title{
UNA BIBLIOTECA MORISCA REQUISADA EN 1592 EN LA VILLA DE MONÓVAR
}

Juan B. Vilar*

Tradicionalmente ha venido considerándose que los moriscos, por las concretas circunstancias históricas en que hubieron de desenvolverse, dada su condición de minoría criptoreligiosa, se hallaban en posesión de una cultura residual más oral que escrita.

Así parecía inferirse de la bibliografía antigua disponible. Desde testimonios coetáneos como los de Luis del Mármol Carvajal ${ }^{1}$, Diego de Mendo$z^{2}$, Ginés Pérez de $\mathrm{Hita}^{3}$, Jaime Bleda ${ }^{4}$ y Marcos de Guadalajara ${ }^{5}$, a monografías clásicas como las de P. Boronat ${ }^{6}$ y P. Longás ${ }^{7}$. La eclosión bibliográfica de los últimos cincuenta $\operatorname{años}^{8}$ ha variado esa realidad. Sobre todo a partir de investigaciones angulares tales como las de H. Lapeyre ${ }^{9}$ J. Reglá ${ }^{10}$,

\footnotetext{
* Universidad de Murcia.

1. Historia del -sic-rebelión y castigo de los Moriscos del Reino de Granada, BAE, XXI, Madrid, 1946 -reedición-.

2. Guerra de Granada hecha por el rey de España Don Felipe II contra los moriscos de aquel Reino, sus rebeldes, BAE, XXI, Madrid, 1946 -reedición-.

3. Guerras civiles de Granada, Cuenca, 1619 -hay reedición en BAE, t. III-.

4. Crónica de los moros de España, Felipe Mey, Valencia, 1618.

5. Memorable expulsión y justísimo destierro de los moriscos de España, N. de Assiayn, Pamplona, 1613; del mismo autor Prodición y destierro de los moriscos de Castilla hasta el valle de Ricote. Con las disensiones de los hermanos Xarifes, y presa en Berberia de la fuerça y puerto de Alarache, N. de Assiayn, Pamplona, 1614.

6. Los moriscos españoles y su expulsión, F. Vives y Mora, Valencia, 1901, 2 vols.

7. Vida religiosa de los moriscos, Imp. Ibérica, Madrid, 1915.

8. Véanse, verbigracia, los repertorios bibliográficos de M. de EPALZA (ad alter), Moros y moriscos en el Levante peninsular (Sharq al-Andalus). Introducción bibliografica, Inst. de Estudios Alicantinos, Alicante, 1983; y M.A. de BUNES IBARRA, Los moriscos en el pensamiento histórico. Historiografía de un grupo marginado, Cátedra, Madrid, 1983.

9. Géographie de l'Espagne morisque, SEVPEN, París, 1959 (hay edición castellana: Valencia, 1986).

10. Estudios sobre los moriscos, Universidad, Valencia, 1964.
} 
T. Halperin Donghi ${ }^{11}$ y L. Cardaillac ${ }^{12}$, y de las colectivas auspiciadas, entre otros, por M. de Epalza, B. Vincent, M. García Arenal y A. Temimi, autores todos ellos por lo demás con obra personal sustantiva.

Sin embargo, es poco lo que se conoce hasta el momento sobre las lecturas, libros y bibliotecas de los moriscos. Y menos todavía sobre su producción literaria. En cuanto se refiere a los moriscos valencianos, que con los de Granada son sin duda quienes ostentaron un superior nivel cultural entre sus correligionarios de España, tanto por su fidelidad a la lengua árabe como a los preceptos religiosos islámicos y a las tradiciones ancestrales musulmanas, la información disponible se reduce a escasas y aisladas noticias de primera mano ${ }^{13}$, y a las más numerosas pero asistemáticas contenidas en la documentación inquisitorial del Tribunal de Valencia ${ }^{14}$, y en menor medida del de Murcia y obispado de Orihuela ${ }^{15}$.

Desafortunadamente, los libros árabes valencianos se han perdido casi en su totalidad. Contadísimos son los ejemplares conservados en diferentes fondos bibliográficos nacionales y extranjeros. $Y$ aun asi, la atribución no siempre es segura.

En cuanto al destino final que corrieron las obras requisadas a los moriscos por los tribunales inquisitoriales de Valencia y Murcia, de lo cual existe referencia documental ${ }^{16}$, apenas se sabe nada. Todo parece indicar que la mayor parte de esos depósitos fueron destruidos en fechas más o menos pró-

11. Un conflicto nacional. Moriscos y cristianos viejos en Valencia, Inst. "Alfons el Magnánim", Valencia, 1980 (recopilación de estudios publicados en París, 1956, y Buenos Aires, 1957).

12. Morisques et Chrétiens. Un affrontement polemique (1492-1640), Ed. Klincksieck, París, 1977, (hay edición castellana: Fondo de Cultura Económica, Madrid, 1979).

13. Vid. L.P. HARVEY, «The Arabic dialect of Valencia in 1595», Al Andalus, 36 (1971), pp. 81-115; id., The literary culture of the Moriscos (1492-1609). A study based on the extant Mss. in Arabic and Aljamia, Oxford University, Oxford, 1958; A.M. LABARTA, «Los libros de los moriscos valencianos», Awraq, 2 (1979), pp. 72-80; M.a del C. BARCELO TORRES, Minorias islámicas en el País Valenciano. Historia y dialecto, Universidad de Valencia-Inst. Hispano Árabe de Cultura, Valencia-Madrid, 1984. Estos estudios remiten a una bibliografía más amplia.

14. A. LABARTA, «Inventario de los documentos árabes contenidos en procesos inquisitoriales contra moriscos valencianos, conservados en el Archivo Histórico Nacional de Madrid (Legajos 548-556)», Al-Qantara, 1 (1980), pp. 115-164; id., "Notas sobre algunos traductores de árabe de la Inquisición valenciana (1565-1609)», Revista del Instituto Egipcio de Estudios Islámicos, 21 (1981-82), pp. 105-134; R. GARCÎA CARCEL, Orígenes de la Inquisición Española: el Tribunal de Valencia, 1478-1530, Península, Barcelona, 1976; id., Herejía y sociedad en el siglo XVI. La Inquisición en Valencia, 1530-1609, Península, Barcelona, 1980.

15. J.B. VILAR, Orihuela, una ciudad valenciana en la España moderna, CAM, Murcia, 1981, 3 vols. (IV, V y VI en J.B. VILAR, Historia de la ciudad y obispado de Orihuela, Murcia, 1977-1982, 8 vols.); id., «La rebelión y dispersión de los moriscos: el caso murciano», en J. PEREZ Villanueva y B. EsCandell Bonet (dirs.), Historia de la Inquisición en España y América, BAC, Madrid, 1984, I, pp. 772-782.

16. Vid. notas 14 y 15 supra. 
ximas a su incautación. En el mejor de los casos, vendidos o dispersados, perdiéndose los pocos ejemplares conservados en sus archivos y anaqueles durante el asalto, saqueo y semidestrucción de las oficinas y establecimientos del Santo Oficio con ocasión de la abolición del Tribunal, según aconteció en Murcia en 1820.

Realidad tan negativa ha podido ser variada en parte mediante el estudio, y en su caso edición, del material documental y bibliográfico conservado en España, con el rescate de una parte de los manuscritos y libros moriscos localizados en el extranjero (en Túnez y Marruecos sobre todo) desde mediados del siglo XIX, y más excepcionalmente por el hallazgo en la Península de varias bibliotecas moriscas, sumergidas en fondos inclasificados hasta el momento, o bien exhumadas al procederse a la reforma o demolición de algún vetusto inmueble. Estas últimas casi siempre en Aragón ${ }^{17}$ y Andalucía, pero también en Valencia ${ }^{18}$.

Esos depósitos bibliográficos, celosamente conservados por sus propietarios tras la forzada conversión al cristianismo en las dos décadas iniciales del siglo XVI, para su uso e incluso reservada circulación, fueron objeto de insistente búsqueda para su destrucción, tanto por sínodos y ordinarios diocesanos como por la Inquisición. Los que se salvaron de un acoso tan tenaz y sistemático fueron sacados clandestinamente de España por sus propietarios antes y durante la general expulsión de los moriscos de 1609-1614, o bien ocultados en sus abandonados inmuebles al amparo de falsas paredes, o en recónditos escondrijos.

17. Es paradigmático por su entidad y relevancia el fondo hallado en Almonacid de la Sierra, a partir de la noticia inicial dada por don Francisco Codera. F. CODERA, «Almacén de un librero morisco encontrado en Almonacid de la Sierra», Boletín de la Real Academia de la Historia, V (1884), pp. 269-276. Vid. también: J. Ribera, M. Asín PALACIOS, M. AlarCón, A. Hulci Miranda, C. GonzÁlez y T. Navarro Tomás, Manuscritos árabes y aljamiados de la Junta [de Ampliación de Estudios], Madrid, 1912. Entre la larga descendencia científica de tan singular colección, cabe espigar estudios como el de F. CORRIENTE, Relatos píos y profanos del ms. aljamiado de Urrea de Jalón. Prólogo de M. J. Viguera, Inst. "Fernando el Católico", Zaragoza, 1990, y J. ZANÓN, «Los estudios de lengua árabe entre los moriscos aragoneses a través de los manuscritos de la Junta», Sharq al-Andalus, 12 (1995), pp. 363-374, que aparte de su interés intrínseco, remiten a amplia y actualizada bibliografía.

18. J. Ribera y TARrago, "Escuela valenciana de calígrafos árabes», Almanaque de "Las Provincias" (Valencia, 1907). Reimpreso en J. RIBERA, Disertaciones y opúsculos, Madrid, 1928, II, pp. 304-308. Más noticias sobre el hallazgo de Albalat de Segart, o de Torongers, marzo de 1904, en M. a del C. BARCELO TORRES, op. cit., pp. 42, 47-48, y «Nuevos fondos arábigo-valencianos: la colección Martínez-Aloy», Al-Qantara, VII (1986), pp. 321-330. Información adicional sobre otros hallazgos documentales y bibliográficos moriscos valencianos en $A$. LABARTA, «Las cuentas del tendero morisco Gerónimo Hoix (Gandía, 1587)», Al-Qantara, III (1982), pp. 135-171; M. ${ }^{a}$ del C. BARCELO TORRES, «Els moriscs de Gandía; els seus papers árabs», Ullal, 2 (1982), pp. 72-73; J.B. VILAR, «Hallazgo de una biblioteca morisca en Potries (Gandia) en 1789», Sharg al-Andalus, 5 (1988), pp. 147-152. 
Uno de los fondos interceptados lo fue en 1592 en la villa de Monóvar, baronía de los Maza en el Vall d'Elda o cuenca media del Vinalopó, obispado de Orihuela, en los confines meridionales del reino valenciano.

Monóvar, como las restantes localidades comarcanas, todas ellas señoríos seculares (Elda, Novelda, Aspe, Crevillente, Elche), era pueblo predominantemente morisco, donde la comunidad veterocristiana apenas representaba la décima parte de su censo. El cómputo de 1597, realizado con la expresa finalidad de conocer el número exacto de cristianos nuevos residentes en la diócesis oriolana para proceder a la erección de las correspondientes parroquias, arroja para Monóvar una población de 280 vecinos, de los cuales 230 eran moriscos ${ }^{19}$. El total de cristianos nuevos computados fue de 2.745 vecinos, unos 12.352 individuos si aplicamos el coeficiente 4,5. Todos ellos moriscos del país, exceptuados 180 residentes en la ciudad de Orihuela, que eran granadinos inmigrados ${ }^{20}$. En total, por tanto, 12.172 repartidos en once lugares: Crevillente, Elche, Aspe, las villas y lugares del valle de Elda, y Orihuela con algunas de sus aldeas ${ }^{21}$.

Este censo resulta más fiable que el publicado sobre fecha imprecisa del siglo XVI por P. Boronat ${ }^{22}$, cuyos datos toma sin duda de T. González ${ }^{23}$. En el de Boronat-González, entre otras imprecisiones, las minorías son aglutinadas por las mayorías, de forma que ambos autores introducen la simplista e irreal distinción entre poblaciones de cristianos viejos y poblaciones de moriscos, cuando es un hecho probado que, salvo contadas excepciones en que por privilegio era vedada la residencia a los conversos de moros o cristianos nuevos, ambas comunidades solían convivir en una misma localidad.

19. Archivo de la catedral de Orihuela (ACO), leg. 1.126: Erección de curatos en los lugares de Moriscos del Obispado de Orihuela, $21 \mathrm{fs}$. [sig. ant.]. Este censo, que tuve la fortuna de hallar en 1978, lo dí a conocer con el estudio correspondiente en el mismo año en la revista especializada de máxima difusión en la época (J.B. VILAR, "Los moriscos de la gobernación y obispado de Orihuela», Al-Andalus, XLIII, fasc. 2 -1978-, pp. 323-367), lo que no sería óbice para que cuatro años más tarde un avispado investigador (Anales de la Universidad de Alicante. Facultad de Derecho, n. 1 -1982-, pp. 243-272) impresionado por la estulticia ajena, y movido de beneméritos sentimientos en favor de "...los estudiosos del tema, que andan bastante a tientas", presentase como "de primera mano", la fuente de referencia, que con signatura renovada vio en el mismo archivo, si bien remitiéndose a un ejemplar localizado "a posteriori" en otro lugar.

20. J.B. VILAR, «Moriscos granadinos en el sur valenciano», Estudis, 9 (1983), pp. 15-47.

21. «Los moriscos de la gobernación y obispado de Orihuela...», tabla 3.

22. Los moriscos españoles..., t. II (apéndice).

23. Censo de población de las Provincias y Partidos de la Corona de Castilla en el siglo XVI. Con varios apéndices para completar la del resto de la Peninsula en el mismo siglo, y formar juicio comparativo con la del anterior y siguiente, según resulta de los libros y registros que se custodian en el Real Archivo de Simatcas, Imp. Real, Madrid, 1829, p. 138. 
Monóvar, con 280 casas pobladas y unos 1.260 habitantes, con una proporción de moriscos de 9 a 1 según queda referido, como las restantes baronías de la zona se hallaba pastoralmente desasistida por carecer de párroco titular. Sus funciones eran asumidas aquí por un clérigo asalariado, designado por el obispo a propuesta del señor, y reducido a arrastar una existencia precaria, sin otro ingreso que las 60 libras anuales que le pasaba el barón con cargo a las 1.644 percibidas por éste en concepto de participación en el producto de los diezmos. Tal era, en efecto, el acuerdo suscrito en 20 de julio de 1498 entre el obispo y cabildo de Cartagena de un lado y don Pedro Maza de otro, éste a la sazón señor temporal, concordia extensible a las otras baronías pertenecientes a los Maza en la gobernación meridional ${ }^{24}$.

Segregada la diócesis de Orihuela de la de Cartagena en 1564, fue mantenido el acuerdo económico mencionado. De forma que el titular del señorío no se avino a incrementar el salario del sacerdote encargado de la cura de almas, reducido como siempre a arrastrar una existencia precaria, y afanoso de abandonar la villa para buscar en otra parte un curato más pingüe.

Siendo Monóvar pueblo de colonos, enfiteutas y jornaleros al servicio de los sucesivos señores locales, absentistas pero atentos a la puntual percepción de sus rentas, y por tanto muy celosos de la protección de unos vasallos que cumplían con exactitud sus obligaciones económicas, tampoco ahora se les prestó demasiada atención desde el punto de vista religioso, dejándoles vivir en sus creencias y costumbres. Tanto era así que el templo parroquial consagrado a San Juan Bautista, levantado sobre el solar que antes ocupase la mezquita, apenas era frecuentado. La feligresía rehuía el contacto con el cura, no buscándole sino en relación con asuntos administrativos referidos a los registros parroquiales. Tampoco le entregaban las preceptivas primicias. Se comprende la desgana con que cumplían sus funciones los desairados rectores, mal pagados por el señor temporal y rechazados por unos feligreses poco o nada receptivos del mensaje evangélico.

Por su parte, los sucesivos obispos Gregorio Gallo de Andrada, Tomás Dassio Abats y Josep Esteve no anduvieron más afortunados en sus esfuerzos de captación proselitista, desplegados con criterios variables pero con mediocres resultados. El primero de los mencionados, canonista castellano que había alcanzado cierto renombre en Trento, mediante los acuerdos del primer sínodo oriolano por él reunido ${ }^{25}$, pretendió que, siquiera, se guardasen las formas en lo que se refiere a la misa dominical, recepción de sacramentos, y lectura y explicación del catecismo en lengua vulgar.

24. Erección de Curatos...

25. Prima Synodus /Oriolana/sub Sanctissimo/Domino nostro Pio V/ Pontif. Max/regnante Invictissimo Rege nostro Catholico Philippo LI/A Gregorio Gallo,/Episcopo Oriolensi habita. / XIX maii. Anno MDLXIX./Murciae, p. 10 y ss. 
Dassio, por su parte, con sus Ordinaçiones ${ }^{26}$, que debió promulgar al comienzo de su pontificado, prolongado por espacio de siete años entre 1578 y 1585, a la vista del fracaso cosechado por su predecesor, renunció a la vana pretensión de hacer variar a corto o medio plazo la negativa situación existente, contentándose con controlarla y hacerla económicamente rentable. A tal fin introdujo un severo arancel de sanciones.

Esteve (o Esteban, como gustaba firmarse este obispo valenciano castellanófilo y castellanófono), fue el único en abordar un vasto programa pastoral, encaminado a obtener la conversión real de los moriscos de su diócesis, que expondría en 1595 en carta a Felipe II ${ }^{27}$, sobre la base de mejorar la formación, selección y retribución del clero destinado a las "aljamas" (término con el que significativamente denominaba a los pueblos de cristianos nuevos, con lo que dejaba fuera de dudas el verdadero carácter de los mismos), la apertura en todas ellas de escuelas dominicales de obligada asistencia para niños y adultos, y la dignificación del culto. En lugares como Monóvar, donde existía una minoría de cristianos viejos, refería el prelado: "...Es necesario que vivan mezclados para que el trato y compañía les haga practicar [a los moriscos] la religión [cristiana]".

En lo demás, sugería que se les prohibiera sus atuendos peculiares, sus tradiciones ancestrales, y en particular el uso de la lengua árabe (pena de "...dos reales cada vez que hablen algarabía"). En contrapartida debería protegérseles de toda vejación o atropello por parte de los cristianos viejos, incluidos los abusos de los respectivos señores, que ellos soportaban de buen grado con tal de que les permitieran mantenerse en sus creencias y costumbres.

Habiendo obtenido Esteve autorización real para su proyecto, lo perfiló dos años más tarde en una reforma parroquial que, con el asentimiento de Roma, no tardó en llevar a la práctica. En lo que a Monóvar concierne asignó al mantenimiento de la fábrica y culto parroquiales los bienes de la antigua mezquita, y designó rector titular residente, quien debería ser instalado en casa rectoral edificada de nueva planta. Dado que la señoría no se avino a recortar su participación en los diezmos para incrementar el salario del cura, el prelado descargó sobre los feligreses esa obligación. A tal fin impuso la obligatoriedad de satisfacer primicias por la totalidad de los frutos recolectados, rebaños, animales domésticos y restantes ingresos, entendiendo ser aquellas "...debidas al párroco por derecho divino" 28 .

\footnotetext{
26. J.B. VILAR, «Las Ordinaçiones del obispo Tomás Dassio, un intento de asimilación de los Moriscos de la diócesis de Orihuela», Les Morisques et leur temps, CNRS, Paris, 1983, pp. 383-410.

27. P. BORONAT, op. cit., II (apéndice).

28. Erección de Curatos...
} 
El segundo sínodo oriolano, celebrado en 1600 , todavía durante el pontificado de Esteve, ratificó estos acuerdos ${ }^{29}$, cuya vigencia sin embargo fue escasa. El edicto de general expulsión de los moriscos -22 de septiembre de 1609 - en lo que a Monóvar se refiere tuvo efecto fulminante. Fue cumplido a finales del mes siguiente, en que se procedió al embarque en Alicante de 250 familias de esta procedencia ${ }^{30}$. Según un informe del obispo de Orihuela, quedaron en la villa solamente 30 casas pobladas ${ }^{31}$, lo que da idea de la magnitud de los efectos sobre la misma del decreto de expulsión, auténtica catástrofe demográfica y económica sin parangón en la historia de esta localidad. Los deportados fueron llevados al enclave español de Orán, desde donde pasaron a diferentes puntos de la inmediata Regencia turca de Argel.

Dos años más tarde doña Ana de Portugal y Silva, por entonces titular de la baronía de Monóvar, daba una carta puebla para proceder a la repoblación de la misma ${ }^{32}$. Dada la escasez de potenciales pobladores y las condiciones de repoblación previstas en la Carta, no excesivamente generosas, los frutos de la misma resultaron más bien modestos. Baste decir que a mediados del siglo XVII (1646) Monóvar contaba apenas con 167 vecinos $^{33}$, unos 750 habitantes, algo más de la mitad de su censo en vísperas de la expulsión de los moriscos.

En el Archivo Histórico Nacional, sección Inquisición, legajo $2.022^{1}$, se contienen, entre otras, las causas vistas en el Tribunal inquisitorial de Murcia, correspondientes al período comprendido entre diciembre de 1591 y noviembre del siguiente año. Entre ellas la sustanciada a cierto Juan Mañai.

Era éste un morisco, vecino de Monóvar y muy anciano (declaró tener... jnoventa años!, edad acaso exagerada dada la corta esperanza de vida en la época, buscando obtener así trato más indulgente), y cuya profesión no consta. De la lectura de la causa se infiere sin embargo tratarse de persona acomodada, al parecer almacenista, comerciante, tendero o carretero, por figurar su domicilio entre los visitados regularmente por agentes fiscales para

29. Synodus oriolana/secunda/sub santiss./D.N. Clemente VIII./Regnante Potentissimo Philippo III/Rege nostro Catholico celebrata. A Rev. D.D. Josepho Stephano/Episcopo Oriolano. Kal. octub./MDC./ Murciae. Apud viduan Philippi Teruel. (s.a.), pp. 28-30.

30. H. LAPEYRE, op. cit, p. 71.

31. Ibidem, p. 82.

32. Carta de población y Capítulos para su gobierno de la Villa y Baronía de Monóvar, 1611, Caja de Ahorros Provincial de Alicante, Alicante, 1977 (n." 10 de Papeles Alicantinos).

33. H. Lapeyre, op. cit., p. 111. Vid. a su vez R. Belando Carbonell y G. SÁnchez Recio, «Monover, una villa de señorío en el siglo XVII», Item. Revista de Ciencias Humanas, 3, pp. 23-40. Sobre el contexto general de la repoblación valenciana tras la deportación de moriscos existen diferentes estudios a partir del de J.R. TORRES MORERA, «Repoblación del reino de Valencia después de la expulsión đe los moriscos», Saitabi, XVI (1966), pp. 121-148. 
comprobar que no ocultase en el mismo mercancías vedadas. Contaba con bienes propios y arraigo en la villa. También con cierta cultura, por cuanto tenía una pequeña biblioteca en casa y hablaba y escribía la lengua árabe, lo que hace presumible que poseyera igual dominio del valenciano, lengua usual en la localidad, y acaso también del castellano, muy utilizado por los moriscos de la gobernación de Orihuela por sus frecuentes conexiones y tratos con los granadinos inmigrados y con sus correligionarios de Murcia.

Mañai presentaba notorios antecedentes heterodoxos. Así lo evidencia el que, en su día, fuese uno de los que se acogieron al edicto de gracia dado para los moriscos islamizantes del reino de Valencia, de forma que "...fue reconçiliado por cosas que confesó haber hecho de la secta de los moros, y con intençión de moro, y hizo la abjuraçión de los otros reconçiliados" 34 .

Un tiempo después fue denunciado por cuatro testigos en el sentido de que, habiendo sido practicado en su casa un registro rutinario por los agentes fiscales de la Generalitat, según era normativo en el reino valenciano, para ver si detectaban mercancías no declaradas o algún otro fraude, "...hallaron que su muger llevaba a esconder un capaço de libros escritos en arábigo, y se los tomaron las guardas, y los entregaron al comisario [local] del Santo Oficio" ${ }^{\prime 35}$.

De cuanto acontenció después da noticia el texto de referencia. El comisario remitió los libros intervenidos al Tribunal inquisitorial de Murcia, en cuya jurisdicción se hallaba la villa de Monóvar desde la creación de aquél en 1488, así como el restante territorio de la gobernación de Orihuela ${ }^{36}$.

Examinados los libros, “...se hallaron todos ellos ser del Alcorán de Mahoma, y donde se enseñaban sus ritos y çeremonias muy particularmente $^{\prime 37}$. Ello sintoniza con la reputación que tenían los moriscos de Monóvar, y los de la cuenca del Vinalopó en general, de ser criptomusulmanes muy observantes $^{38}$, ya que a diferencia de los de otros lugares, que se regían preferentemente por costumbres y por tradiciones orales, éstos lo hacían siguiendo los preceptos consignados en libros celosamente ocultados, de los que circulaban clandestinamente copias en árabe y en lengua vulgar aljamiada.

34. AHN. Inquisición, leg. 2.0221: Relación de causas que se han despachado en el Santo Oficio de la Inquisición de Murcia, desde ocho de diciembre del año noventa y uno, hasta fin de noviembre de este año de 1592: De los reconciliados por cosas de la secta de Mahoma, f. $4 \mathrm{v}$.

35. Ibidem.

36. J. CONTRERAS y J.P. DEDIEU, «Geografía de la Inquisición española. La formación de distritos, 1470-1820», Hispania, 144 (1980), pp. 71-81.

37. Archivo Histórico Nacional (AHN), Inquisición, leg. 2.022 1 : Relación ..., fols. 4v-5v.

38. J.B. VIL.AR, Los siglos XIV y XV en Orihuela, CAM, Murcia, 1977, p. 352 (t. III de J.B. VILAR, Historia...); id., «La rebelión y dispersión de los moriscos...». 
Se comprende el empeño de sínodos y obispos de erradicar la utilización del árabe entre los nuevos convertidos, y en particular en localizar y recoger los libros arábigos: “...mandamos -dispone el mitrado Dassio en sus Ordinaçiones ${ }^{39}$ - que todos los que tuvieren libros de alcorán o secta de maho$\mathrm{ma}$, o de otras çeremonias moriscas, los lleven y traygan ante nos o nuestro provisor so pena que seran castigados".

Este acuerdo contaba, entre otros precedentes, con varios similares emitidos por el sínodo valenciano reunido por el mitrado Jorge de Austria en fecha indeterminada, si bien R. Benítez y E. Císcar ${ }^{40}$ lo sitúan en 1540, y en la redacción de cuyas actas intervino muy activamente Antonio Ramírez de Haro, obispo de Segovia, y uno de los comisarios destacados en tierras de Valencia por el inquisidor general Manrique. También en los acuerdos de otro sínodo valenciano posterior, el de 1565, presidido y coordinado por el arzobispo Martín Pérez de Ayala ${ }^{41}$, asamblea que, a su vez, no dejó de beneficiarse de la experiencia acumulada en el sínodo de Guadix de $1554^{42}$, reunido por el propio Ayala a su paso por la sede andaluza.

Más inmediatos cronológica y geográficamente al asunto Mañai fueron los acuerdos adoptados al respecto en el ya mencionado sínodo celebrado en Orihuela en 1569 bajo los auspicios del obispo Gallo de Andrada, en que fue concedida considerable atención a la problemática morisca heredada de la época en que el territorio perteneció a la mitra de Cartagena ${ }^{43}$. Cabe reseñar, a su vez, las Ordenanzas del mitrado A. González Gallego, y una Instrucción sinodial cartaginense, ambas de $1571^{44}$, acuerdos ambos referidos más a los granadinos inmigrados que a los moriscos de la tierra.

39. Cfr. J.B. VILAR, «Las Ordinaçiones...», p. 408.

40. «La Iglesia ante la conversión y expulsión de los moriscos», en R. GARCía VILLOSLADA (dir.), Historia de la Iglesia en España, BAC, Madrid, 1979, IV, p. 268. A su vez véase de R. BENÍl'EZ SANCHEZ-BLANCO, «Un plan para la aculturación de los Moriscos Valencianos: Les Ordinacions de Ramirez de Haro (1540)», Les Morisques et leur temps, CNRS, París, 1983, pp. 125157; id., «Proyectos de aculturación y resistencia morisca en Valencia: de Tomás de Villanueva a Juan de Ribera», en A. TEMIMI (coord.), Religión, Identité ét sources documentaires sur les morisques Andalous, ISD, Tunis, 1984, I, pp. 53-65; id., «L'Eglise et les Morisques», en L. Cardaillac, Les Morisques et l'Inquisition, PUBLISUD, París, 1990, pp. 65-80.

41. CONCILIUM PRO/VINCIAE VA/LENTINUM./ Celebratu anno MDLXV, Oficina Ioannis Mey, Valentiae, 1566, p. 183. Sobre la figura y obra de Ayala véase nota 40 supra. También: R. García CARCEl, "Estudio crítico del catecismo de Ribera-Ayala», en Les Morisques et leur temps..., pp. 159-168.

42. A. Gallego Burín y A. Gamir Sandoval, Los moriscos del reino de Granada, según el sínodo de Guadix de 1554, Granada, 1968, pp. 33-126.

43. Véase nota 25 supra.

44. J.B. VILAR, «Un intento de aculturación de los granadinos internados en Murcia y su reino. Ordenanzas del obispo A. González Gallego e Instrucción sinodial cartaginense de 1571", en A. TEMIMI (coord.), Religion, identité et sources...., II, pp. 167-187. 
El Tribunal de Murcia anduvo diligente en el caso Mañai, sin tener con el reo el menor miramiento. Ello no era de extrañar habida cuenta el rigor que los pesquisidores murcianos solían usar en las causas relacionadas con Orihuela y su gobernación, que en vano habia intentado hasta el momento sacudirse la jurisdicción de aquel Tribunal, al objeto de impedir que los reos fueran sacados de su territorio para ser juzgados en Murcia y en lengua castellana ${ }^{45}$.

En suma, "...con esta informaçión. [Juan Mañai] fue preso y traido a las cárceles [murcianas]". Interrogado el acusado, y examinado a su vista el lote bibliográfico incautado, reconoció "...haberse hallado en su poder los dichos libros arábigos, y que algunos de ellos eran de la secta de Mahoma, y otros de cuentas" 46 . No obstante, intentó exculparse refiriendo "...que los dichos libros eran de su suegro, que haçía muchos años que había muerto...", táctica por lo demás bastante común en estos casos, en que los presuntos implicados solían hacer recaer toda responsabilidad en difuntos y ausentes.

Interrogado de nuevo, reconoció "...saber leer y escribir en arábigo", circunstancia que de entrada le incluía en el peligroso grupo de los depositarios y transmisores de la fe, ritos y tradiciones islámicas, a que se refieren Longás $^{47}$, Cardaillac ${ }^{48}$ y Epalza ${ }^{49}$, y por lo mismo especialmente sospechoso de delitos de islamismo. Por ello, si bien "...negó haber leydo en ellos, ni haber enseñado a nadie ${ }^{\prime 50}$, todo parecía acusarle. Como se mantuviera firme en su declaración ("...en todo el discurso del proceso perseveró en esto") e irritados los pesquisidores con lo que debían conceptuar como contumacia del reo, acordaron administrarle tormento, "...el qual se le dio", pero Mañai "...perseveró en su negativa".

No obstante la firmeza demostrada en todo momento por el acusado, al Tribunal debió parecerle que existían evidencias sobradas de culpabilidad. En consecuencia condenó al reo a salir vestido con sanbenito para oír la sentencia y abjurar de vehementi públicamente sus errores, bien con los otros condenados en el previsto auto a celebrar en Murcia en fecha inmediata, bien enviándole a su punto de procedencia para que lo hiciera en la iglesia de su pueblo a hora de misa mayor, según era costumbre. Al propio tiempo se le condenaba a doscientos azotes, multa de doce ducados consignados a la fá-

45. J.B. VILAR, «La rebelión y dispersión...», p. 773.

46. AHN, Inquisición, leg. 2.022 $2^{1}$ : Relación..., f. 5 r.

47. Vida religiosa de los moriscos...

48. Morisques et chrétiens...

49. M. de Epalza, Los moriscos antes y después de la expulsión, Mapfre, Madrid, 1992.

50. AHN, Inquisición, leg. 2.022 $2^{1}$ : Relación..., f. 5r. Sobre ésta y otras causas sustanciadas a moriscos en el Tribunal de Murcia, véase Archivo Diocesano de Murcia (ADM), Instrucciones y cartas acordadas, antiguas y modernas, del Santo Oficio [de Murcia] s.f. 
brica del templo parroquial de San Juan Bautista de Monóvar, y a dos años de destierro de su villa natal.

Dura sentencia para un anciano en el final de sus días, que contrasta con la indulgencia usada en general por el Tribunal de Murcia con los moris$\cos ^{51}$. Una indulgencia reservada sin embargo al morisco iletrado e ignorante, convicto de rutinarias prácticas ancestrales, que no a quienes conocían la lengua árabe y poseían libros en ese idioma, tratados como inductores a la apostasía, y por tanto equiparados a los odiados judaizantes y a los no menos aborrecidos disidentes protestantes.

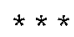

\section{APÉNDICE DOCUMENTAL}

Juan Mañai, morisco, veçino de la Villa de Monobar, de edad de nobenta años. Este, en tiempo que hubo edicto de graçia para los moriscos del Reino de Valençia, fue reconçiliado por cosas que confesó haber hecho de la secta de los moros, y con intención de moro, y hizo la abjuraçión de los otros reconçiliados. Después de lo qual, el reo fue testificado con quatro testigos, de que buscándole la casa las guardas del general, que es cierto derecho del reyno de Valençia, para ver si hallaban algún fraude en su casa, de lo que tocaba al derecho, hallaron que su muger llebaba a esconder un capaço de libros escritos en arábigo, y se los tomaron las guardas, y los entregaron al comisario.

El qual los embió al Santo Oficio, donde se interpretaron, y se hallaron todos ellos ser del Alcorán de Mahoma, y donde se enseñaban sus ritos y çeremonias muy particularmente. Con esta informaçión fue preso y traido a las cárceles. Y él confesó haberse hallado en su poder los dichos libros arábigos, y que algunos de ellos eran de la secta de Mahoma, y otros de quentas, y que los dichos libros eran de su suegro, que haçía muchos años que había muerto, los quales reconoçió.

Negó haber leydo en ellos, ni haber enseñado a nadie, aunque declaró saber leer y escribir arábigo, y en todo el discurso del proçesso perseueró en esto. $Y$ se votó a tormento, el qual se le dio, y perseueró en su negativa. Votóse a que este reo saliese al auto, o a una yglesia, a oir su sentençia en forma de penitente y que abjurase de behementi, y que se le diesen dosçientos azotes, y desterrado de la Villa de Monobar por dos años, y condenado en doçe ducados para la fábrica de la iglesia de Monobar. Executose.

AHN, Sección Inquisición, leg. $2.022^{1}$, fols. 4v-5r: Relación de las causas que se han despachado en el Santo Oficio de la Inquisición de Murcia, desde ocho de diciembre del año de noventa y uno, hasta fin de noviembre de este año de 1592: De los reconciliados por cosas de la secta de Mahoma.

51. J.B. VILAR, «L'Inquisition de Murcie», en L. Cardaillac, Les Morisques et l'Inquisition, PUBLISUD, París, 1990, pp. 241-257. [Hay traducción castellana con el título «Moriscos de la diócesis de Cartagena», recogida en el volumen misceláneo: J.B. VILAR, Los moriscos del reino de Murcia y obispado de Orihuela, Prólogo de M. de Epalza, R. Academia Alfonso X el Sabio, Murcia, 1992, pp. 27-61]. 


\section{RESUMEN}

La tesis tradicional, según la cual los moriscos formaban una minoría iletrada, con cultura residual más oral que escrita, no puede ya sustentarse a la vista de los numerosos estudios realizados en los últimos cincuenta años, sobre todo los referidos a bibliotecas y aportaciones literarias, tanto en árabe como en castellano aljamiado.

El fortuito hallazgo en 1592, con ocasión de un registro rutinario practicado por agentes fiscales de la Generalitat de Valencia para detectar mercancías vedadas, en la casa de un mercader morisco de la villa de Monóvar de una biblioteca formada por libros “...del Alcorán de Mahoma, y donde se enseñaban sus ritos y çeremonias muy particularmente", y la circunstancia de que el propietario supiera "...leer y escribir en arábigo", es un testimonio más sobre el morisco arabófono y amante de los libros.

\section{ABSTRACT}

The traditional thesis, according to which the Moorish formed an illiterate minority, with residual culture more verbal than written, can not be sustained any more. This is clear if we keep in mind the numerous studies -mainly the ones referring to libraries and literary contributions, not only in Arabic but also in Spanish written in Arabic characters- accomplished in the last fifty years.

The fortuitous finding in 1592 of a library formed by books "... of the 'Alcorán' of Mahomet, in which his rites and ceremonies, very particularly, were taught", and the fact that the owner could "...read and write in Arabic", is another testimony of Moorish, being Arabists and lovers of books. This finding took place with occasion of a regular search practised by fiscal agents of the Generalitat of Valencia to detect restrained commodities, in the house of a Moorish merchant in the villa of Monovar. 